\title{
Review Article \\ The Cardiorenal Syndrome: A Review
}

\author{
B. N. Shah ${ }^{1}$ and K. Greaves ${ }^{2}$ \\ ${ }^{1}$ Department of Cardiology, Wessex Cardiothoracic Centre, Southampton University Hospital, Southampton, UK \\ ${ }^{2}$ Department of Cardiology, Poole General Hospital and Bournemouth University, Longfleet Road, Poole, Dorset BH15 2JB, UK
}

Correspondence should be addressed to K. Greaves, kim.greaves@poole.nhs.uk

Received 13 September 2010; Accepted 21 November 2010

Academic Editor: Mitchell H. Rosner

Copyright (C) 2011 B. N. Shah and K. Greaves. This is an open access article distributed under the Creative Commons Attribution License, which permits unrestricted use, distribution, and reproduction in any medium, provided the original work is properly cited.

Cardiorenal syndrome (CRS) is the umbrella term used to describe clinical conditions in which cardiac and renal dysfunctions coexist. Much has been written on this subject, but underlying pathophysiological mechanisms continue to be unravelled and implications for management continue to be debated. A classification system-incorporating five subtypes-has recently been proposed though it has yet to permeate into day-to-day clinical practice. CRS has garnered much attention from both the cardiological and nephrological communities since the condition is associated with significant morbidity and mortality. Renal dysfunction is highly prevalent amongst patients with heart failure and has been shown to be as powerful and independent a marker of adverse prognosis as ejection fraction. Similarly, patients with renal failure are considerably more likely to suffer cardiovascular disease than matched subjects from the general population. This paper begins by reviewing the epidemiology and classification of CRS before going on to consider the different pathological mechanisms underlying cardiorenal dysfunction. We then focus on management strategies and conclude by discussing future directions in the diagnosis and management of patients suffering with CRS.

\section{Introduction}

The heart is responsible for supplying the organs and tissues of the body with blood, and the kidneys, amongst other functions, play an integral role in fluid balance and salt homeostasis. It should therefore come as little surprise that renal dysfunction frequently accompanies cardiac failure and that cardiac dysfunction frequently accompanies renal failure. This interdependent relationship has come to be known as the "cardiorenal syndrome" [1]. This phrase has been in use since 2004 [2], but despite generating a plethora of papers in the literature and being discussed at length in dedicated conferences, CRS has until very recently lacked a universally accepted definition, and numerous key questions remain unanswered [3]. What is the true prevalence? What is the long-term prognosis? What is the exact underlying pathophysiology? We shall cover the epidemiology, pathophysiology, and current management of CRS in this paper, but we will begin with brief case histories which help demonstrate the heterogeneity of patients who fall under the umbrella term of CRS.
Case 1. A 63-year-old patient with known severe heart failure and chronic renal impairment (baseline creatinine $190 \mathrm{mmol} / \mathrm{L}$, estimated glomerular filtration rate (eGFR) $23 \mathrm{mLs} / \mathrm{min}$ ) was admitted with acute decompensated heart failure (ADHF). Creatinine on admission was similar to baseline, but over the next week renal function deteriorated significantly (urea $51.1 \mathrm{mmol} / \mathrm{L}$, creatinine $503 \mathrm{mmol} / \mathrm{L}$, eGFR 8 ) requiring inotropic support and then haemofiltration. Her inpatient stay lasted 7 weeks, of which over half was spent on high dependency or intensive care units. Unfortunately, she died from progressive pump failure several weeks after admission.

Case 2. A 31-year-old previously fit and well Indian man was admitted with a two-week history of malaise and a 2-day history of hemoptysis. Admission blood tests revealed urea level of $20 \mathrm{mmol} / \mathrm{L}$ and creatinine level of $1100 \mathrm{mmol} / \mathrm{L}$. Bedside echocardiography revealed moderate global systolic dysfunction indicating probable uraemic cardiomyopathy. A renal biopsy confirmed the diagnosis of glomerulonephritis. After his first three sessions of 
hemodialysis, echocardiography was repeated and revealed normal systolic function.

Case 3. A 32-year-old lady developed end-stage renal failure secondary to type 1 diabetes mellitus. She commenced hemodialysis in 2007, and just prior to this, transthoracic echocardiography revealed concentric ventricular hypertrophy and severely impaired systolic function. 6 months after she had been started on hemodialysis, repeat echocardiography revealed marked improvement in systolic function, with LV dysfunction now only mild rather than severe.

Case 4. A 28-year-old fit gentleman, with no past medical history, was admitted feeling unwell for the past 3 days. He was extremely ill when first seen: temperature $40^{\circ} \mathrm{C}$, BP $70 / 35 \mathrm{mmHg}$, and pulse rate 130 . Initial blood tests revealed marked leukocytosis (white cell count $41.5 \times 10^{9} / \mathrm{L}$, neutrophil count $\left.38.5 \times 10^{9} / \mathrm{L}\right)$ and acute renal failure (urea $6.2 \mathrm{mmol} / \mathrm{L}$ and creatinine $184 \mathrm{mmol} / \mathrm{L}$ ). Transthoracic echocardiography revealed severely impaired systolic function. He was diagnosed with septic shock and treated with fluids and broad-spectrum intravenous antibiotics. In less than 72 hours, he was feeling significantly better and renal function had returned to normal. Numerous blood and urine cultures and throat swabs failed to yield a culpable organism. Repeat echocardiography one week later revealed normal systolic function.

All of these patients had coexistent cardiac and renal dysfunction but clearly with grossly different underlying pathology and, therefore, prognoses.

\section{Epidemiology}

Renal dysfunction is unfortunately extremely prevalent in patients with congestive cardiac failure (CCF), and the associated statistics make sombre reading. Data from the Acute Decompensated Heart Failure National Registry (ADHERE) of over 100,000 patients (admitted with ADHF) revealed that almost one third of patients have a history of renal dysfunction [4]. Another study found that, in a survey of outpatients with congestive cardiac failure, 39\% patients in New York Heart Association (NYHA) class 4 and 31\% of patients in NYHA class 3 had severely impaired renal function (creatinine clearance $<30 \mathrm{mls} /$ minute) [5]. Baseline renal function is as important an adverse prognostic marker as ejection fraction and NYHA functional class [6]. Elevated serum creatinine on admission to hospital with ADHF and worsening renal function during admission for ADHF have both been shown to predict prolonged hospitalisation, increased need for intensive care facilities, and increased mortality $[7,8]$.

Similarly, renal failure is clearly linked with increased adverse cardiovascular outcomes. Almost $44 \%$ of deaths in patients with end-stage renal failure (ESRF) are due to cardiovascular diseases [9], and a 2006 meta-analysis indicated that patients with ESRF are more likely to die from cardiovascular causes than from renal failure itself [10]. Death from cardiovascular causes is $10-20$ times more common in patients with chronic renal failure than in matched segments of the general population [11]. Half of patients commencing hemodialysis will suffer a myocardial infarction within the following two years, and mortality in this patient population is high [12]. Increased myocardial mass (i.e., left ventricular hypertrophy) — which increases myocardial oxygen demand-is increased in mild-to-moderate as well as more advanced stages of renal failure [13].

On the other hand, treatment of renal dysfunction can improve cardiac function, although the majority of this evidence comes from ESRF patients receiving kidney transplants. A study of over 100 dialysis patients with known heart failure who underwent renal transplantation showed an improvement of ejection fraction from $32 \%$ to $52 \%$ and over two thirds of patients had complete normalisation of cardiac function [14]. There are a few other such reports, albeit, all in the transplant population [15-17].

\section{Classification: Cardiorenal or Renocardiac?}

CRS has, in the absence of a generally accepted definition, usually been perceived as renal dysfunction secondary to chronic cardiac dysfunction (i.e., heart failure). However, this clearly failed to address the numerous other instances in which cardiac and renal dysfunction coexist. Ronco et al. first proposed a five-part classification scheme for the cardiorenal syndromes in 2008 [18], and this has since been incorporated into the report from a consensus conference held in the same year [19]. The classification system is outlined in Table 1 but essentially recognises the multiple ways in which cardiorenal dysfunction occurs and defines the primary and secondary organ dysfunction in each case. This consensus group defined CRS as "disorders of the heart and kidneys whereby acute or chronic dysfunction in one organ may induce acute or chronic dysfunction of the other" [18]. This phraseology was chosen as it helps explain the bi-directional nature of the various syndromes. Bongartz and colleagues proposed the "cardiorenal connection" [20] as an addition to the haemodynamic framework (on the control of extracellular fluid volume (ECFV)) developed by the late physiologist Arthur Guyton and termed this the "severe cardiorenal syndrome" (SCRS). They stated that SCRS is a syndrome with "accelerated and extensive cardiovascular disease that has distinct properties not occurring in conditions that affect either organ alone" [20]. They proposed the renin-angiotensin-aldosterone system (RAAS), balance between nitric oxide (NO) and reactive oxygen species (ROS), inflammation, and sympathetic nervous system (SNS) as circuits within the cardiorenal connection. Derangement of any connector was thought to initiate a vicious downward spiral culminating in disturbance in the other connectors and culminating in cardiac and renal dysfunction via common final pathophysiological pathways. However, this terminology has not been widely adopted.

\section{Pathophysiology}

As our knowledge of CRS expands, it is becoming increasingly clear how complex the interaction between heart and 
TABLE 1: Schematic of the classification system proposed by Ronco et al. [18] for subdivision of CRS into 5 subtypes based upon aetiology of dysfunction.

\begin{tabular}{lcll}
\hline CRS type & Name & Description & Example \\
\hline 1 & Acute cardiorenal & $\begin{array}{l}\text { Acute cardiac dysfunction leading to acute kidney } \\
\text { injury }\end{array}$ & $\begin{array}{l}\text { Acute coronary syndrome causing acute heart } \\
\text { failure and then renal dysfunction } \\
\text { Chrongestive cardiac failure }\end{array}$ \\
2 & Chronic cardiorenal & $\begin{array}{l}\text { Chronic heart failure leading to renal dysfunction } \\
\text { Acute kidney injury leading to acute cardiac } \\
\text { dysfunction }\end{array}$ & $\begin{array}{l}\text { Uraemic cardiomyopathy secondary to acute } \\
\text { renal failure } \\
\text { Left ventricular hypertrophy and diastolic heart } \\
\text { failure secondary to renal failure }\end{array}$ \\
4 & Acute renocardiac renal failure leading to cardiac & $\begin{array}{l}\text { Systemic condition causing cardiac and renal } \\
\text { dysfunction }\end{array}$ & Septic shock, vasculitis \\
\hline
\end{tabular}

kidneys is once one organ becomes diseased. We shall explore these mechanisms in greater detail in this section of the paper.

4.1. Old Paradigms Revisited: Beyond the Low-Flow Hypothesis. Conventional thinking for decades held that the progressive deterioration in renal function in heart failure patients was primarily as a result of reduced renal blood flow secondary to reduced cardiac output [21]. Inadequate renal afferent flow was said to activate the reninangiotensin-aldosterone system (RAAS) leading to fluid retention, increased preload, and thus worsening pump failure. However, recent work suggests that, though correct, this is a very narrow and incomplete picture.

The Evaluation Study of Congestive Heart Failure and Pulmonary Artery Catheterization Effectiveness (ESCAPE) trial [22] assessed pulmonary artery catheter-guided management of over 400 patients admitted with ADHF. It found no correlation between baseline renal function and cardiac index, and improvement of the latter did not result in improved renal function. Others have also found that improved cardiac index or reduced wedge pressure during pulmonary artery catheter-guided management failed to predict improvement in renal function [23, 24]. Additionally, worsening renal function has been demonstrated in ADHF patients despite normal systolic function (ejection fraction) [25], and thus, presumably, renal blood flow. In combination, these data suggest much more than simply reduced renal blood flow as an explanation for CRS.

4.2. The Renin-Angiotensin-Aldosterone System (RAAS): Friend Becomes Foe. Activation of the RAAS by reduced perfusion pressure is a protective mechanism against potentially dangerous conditions like haemorrhage. Unfortunately, when chronically stimulated-as in both heart and renal failure-the pathophysiological consequences are severe and deleteriously affect function of both organ systems. Renin is produced in the juxtaglomerular apparatus of the kidneys and catalyses the conversion of angiotensinogen I to angiotensinogen II, which is subsequently turned into angiotensin II (Ang II) by angiotensin-converting enzyme (ACE).
Ang II has numerous negative effects upon the cardiovascular system in heart failure patients, increasing both preload and afterload and thus myocardial oxygen demands. The main changes induced by Ang II are illustrated in Figure 1, but one of the most important recent advances has been recognition of the promotion of vascular inflammation [26]. Ang II activates the enzyme NADPH oxidase in endothelial cells, vascular smooth muscle cells [27], renal tubular cells [28], and cardiomyocytes [29]. This leads to the formation of ROS, mostly superoxide. A growing body of evidence suggests that ROS are responsible for the processes of aging, inflammation, and progressive organ dysfunction [30]. Nitric oxide (NO) is responsible for vasodilation and natriuresis and assists in renal control of ECFV. Superoxide antagonises these effects [31] but also reduces bioavailability of NO. Oxidative stress damages DNA [32], proteins [33], carbohydrates [34], and lipids [35] and also shifts cytokine production towards proinflammatory mediators such as interleukin-1, interleukin-6, and tumour necrosis factor alpha [36]. Interleukin-6 also stimulates fibroblasts leading to increased cardiac and renal fibrosis.

4.3. The Sympathetic Nervous System (SNS) in CRS. SNS activation is initially a protective mechanism in CCF patients, akin to RAAS activation. The aim is to maintain cardiac output by positive chronotropic and inotropic effects on the myocardium. Unfortunately, chronic SNS activation also results in numerous negative effects upon the cardiovascular system and kidneys. SNS overactivity leads to reduction in beta-adrenoceptor density within myocardium and also reduced adrenoceptor sensitivity in both renal [37] and cardiac failure [38]. Catecholamines are also thought to contribute to left ventricular hypertrophy seen in some patients [39]. SNS activation leads to increased cardiomyocyte apoptosis [40] and increases the release of the neurohormone Neuropeptide Y (NPY). NPY is a vascular growth promoter leading to neointimal formation (and thus atherosclerosis) [41], induces vasoconstriction, and also interferes with normal immune system function [42]. Renal sympathetic denervation in patients with resistant hypertension significantly improved renal function in one quarter of patients [43], and bilateral renal nerve ablation has been shown to reduce blood pressure at one-year followup 


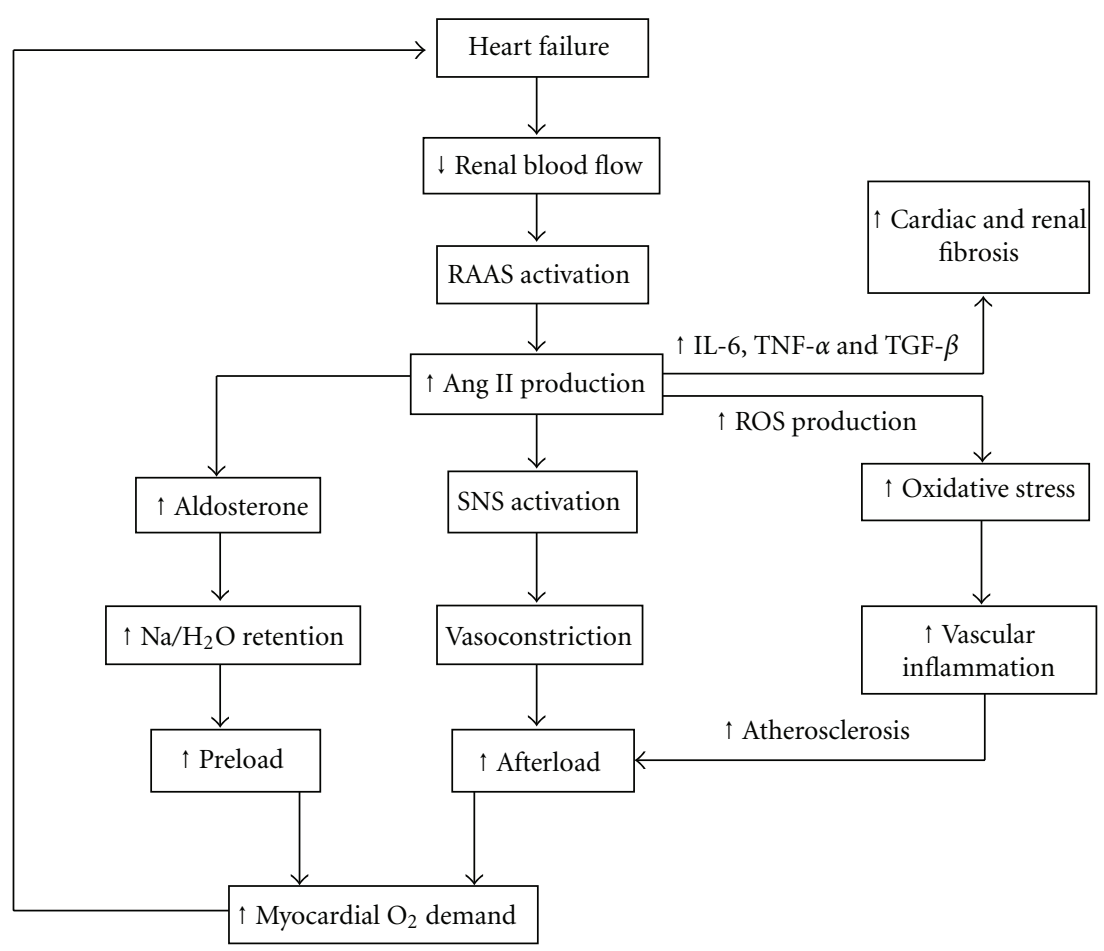

FIGURE 1: Illustration of the pathophysiological pathways activated by angiotensin II. Both preload and afterload are ultimately increased, leading to worsening cardiac and renal function (IL-6 = Interleukin 6; TNF- $\alpha=$ Tumour necrosis factor alpha; TGF- $\beta=$ Transforming growth Factor beta; ROS = Reactive oxygen species).

[44]. However, these therapies have not been tested in the heart failure population and thus still requires further evaluation.

\subsection{Intraabdominal Hypertension: Underrecognised or Over-} emphasised? Heart failure is marked by an elevation in central venous pressure which reduces the perfusion gradient across the renal capillary bed. Studies performed in the early part of the last century demonstrated that rising renal venous pressures could reduce or even abolish urine production [45], and rising renal venous pressure was more important than falling arterial (perfusion) pressure in this setting. Extrinsic compression of renal veins has also been shown to compromise renal function [46].

Intraabdominal pressure (IAP) is said to be elevated when $>8 \mathrm{mmHg}$, and intraabdominal hypertension has been defined as a pressure $>12 \mathrm{mmHg}$ [47]. A study of 40 patients admitted with ADHF found that 24 had an IAP $>8 \mathrm{mmHg}$ though none had abdominal symptoms. The degree of reduction of IAP with diuretic treatment correlated with an improvement in renal function [48]. The ESCAPE trial found that baseline right atrial pressure, but not arterial blood flow, correlated with baseline serum creatinine [22].

Patients with baseline renal dysfunction or worsening renal function after admission have significantly elevated central venous pressure compared to those with less or no renal dysfunction [49]. Additionally, elevated jugular venous pressure on physical examination is associated with higher baseline serum creatinine and increased risk of hospitalisation due to $\mathrm{ADHF}$ and death due to pump failure [50].

4.5. The Cardiorenal Anaemia Syndrome (CRAS). CRAS was first described almost a decade ago by Silverberg et al. as "a vicious cycle of deterioration that leads to poor outcomes, including faster progression to ESRF and further progression of congestive heart failure" [51]. Their simple model suggested anaemia as a condition induced by dysfunction of either organ but also exacerbating dysfunction of either organ. Anaemia is present in over one-third of CRS patients [52]. The Candesartan in Heart Failure: Assessment of Reduction in Morbidity and Mortality (CHARM) study suggested that anaemia was an independent adverse prognostic factor in CCF patients [53]. There has, however, like for CRS, been a lack of consensus over the true definition, significance, and management strategy for patients with CRAS (if even such a "syndrome" exists). This has mainly stemmed from a lack of large-scale randomised controlled trials to guide management.

Anaemia is widely thought to have a multifactorial aetiology in patients with CKD or CCF, but iron deficiency is thought to play a prominent role in both $[54,55]$. Some evidence does suggest benefit from treatment of iron deficiency in such patients. The Ferinject Assessment in patients with Iron deficiency and chronic Heart Failure (FAIR-HF) study assessed intravenous (IV) iron therapy in 459 symptomatic CCF patients with iron deficiency. It demonstrated that the treatment group had a significant 
improvement in heart failure symptoms, exercise capacity, and quality of life irrespective of whether they actually had underlying anaemia or not [56]. Long-term safety data on the newer dextrans-free IV preparations are still awaited, but IV iron does appear to be emerging as an important therapy in patients with CRAS. However, current European guidelines for the management of heart failure (published before results of trials such as FAIR-HF were available) describe correction of anaemia in CCF patients as "unproven" and "not established as routine therapy" [57].

The role of erythropoietin stimulating agents (ESAs) is also controversial due to conflicting evidence. Erythropoietin is a cytokine produced in the kidneys that is essential for red blood cell production. Erythropoietin levels are reduced in renal failure but frequently elevated in heart failure. Scientific studies have shown that erythropoietin protects cardiomyocytes from apoptosis $[58,59]$ and that the mechanism appears to be upregulation of endothelial nitric oxide synthase [60]. A study of 26 heart failure patients with anaemia who received ESA found significantly improved exercise capacity which appeared to be principally due to increased oxygen delivery due to higher haemoglobin concentration [61]. However, studies have shown that patients with CCF have elevated endogenous erythropoietin levels and that this is associated with poorer survival independent of haemoglobin level $[62,63]$. An additional study showed that an erythropoietin level higher than expected was an independent predictor of increased mortality even after adjustment for possible confounding variables [64]. Although initial small studies suggested benefit in correcting anaemia due to CKD with ESAs, three large multicentre phase III trials all had negative outcomes and put a severe question mark over the future of these agents. The Cardiovascular Risk Reduction by Early Anaemia Treatment with Epoetin Beta (CREATE) trial found that correcting anaemia early in patients with renal failure does not reduce their risk of cardiovascular complications [65]. The Trial to Reduce Cardiovascular Events with Aranesp Therapy (TREAT) study found that diabetic patients with renal failure and moderate anaemia had no benefit from receiving ESA and in fact had a statistically higher risk of stroke [66]. Finally, the Correction of Hemoglobin and Outcomes in Renal Insufficiency (CHOIR) trial found that aiming for a higher haemoglobin level in CKD patients with anaemia was associated with a higher risk of adverse outcome including death, hospitalisation for heart failure, or myocardial infarction [67]. A randomised trial of two dosing regimens of the ESA darbepoetin alfa in patients with heart failure and anaemia showed no improvement in NYHA class, LV ejection fraction, or Minnesota Living with Heart Failure questionnaire score [68]. Consequently, the routine use of ESA therapy to increase haemoglobin levels in anaemic CCF patients does not have a sound evidence base.

\section{Management of CRS}

Medical management of patients with concomitant cardiac and renal dysfunction remains tremendously challenging, and this is exacerbated by the fact that the vast majority of trials providing evidence for treatments in heart failure excluded patients with significant renal impairment [69]. The heterogeneous nature of patients with CRS also poses unique challenges with no single success-guaranteed therapy.

5.1. Diuretics: Not as Safe as Commonly Perceived? There is limited trial data proving mortality benefit for diuretics in CRS, but they have long been deemed an essential management strategy in these patients. Data from the ADHERE registry suggests that $81 \%$ of patients were using chronic diuretic therapy at the time of admission with ADHF [4]. Studies have shown, however, that furosemide decreases GFR in many patients [70], and higher doses of diuretics are independently associated with sudden cardiac death or death from pump failure [71, 72]. Furosemide also stimulates the RAAS and can thus increase fibrosis [30]. A systematic review and meta-analysis on the use of loop diuretics in management of patients with acute kidney injury found no mortality benefit, though there was a shorter required duration of renal replacement therapy [73]. A large observational cohort study-examining the use of diuretics in intensive care patients with acute renal failure-found a significantly increased risk of death or nonrecovery of baseline renal function in the patients receiving diuretics [74]. However, the two papers mentioned above looked at all mechanisms of renal dysfunction, not just the heart failure population. There is unfortunately a dearth of high-quality randomised controlled evidence to support or refute the use of diuretics in patients with cardiac and renal dysfunction. Therefore, in the absence of definitive data proving harm in heart failure population, diuretics should not be withheld from volume-overloaded patients.

Diuretic resistance is frequently used as a surrogate marker of poor prognosis in CCF patients. The most probable culpable mechanisms are inadequate diuretic dose, excessive sodium intake, delayed intestinal absorption due to gut mucosal oedema, decreased diuretic excretion into urine, and increased sodium reabsorption from other parts of the nephron not blocked by loop diuretics (e.g., distal convoluted tubule) $[75,76]$. Concomitant use of nonsteroidal antiinflammatory drugs can also contribute to diuretic resistance by diminishing synthesis of vasodilator and natriuretic prostaglandins [77].

In such patients there are several management options. Firstly, one should bear in mind that furosemide does not have a smooth dose-response curve, meaning that no natriuresis would occur until a threshold rate of drug excretion is reached [78]. Consequently, a patient not responding to $40 \mathrm{mg}$ furosemide should have the dose doubled to $80 \mathrm{mg}$ rather than the frequency doubled to twice daily. Secondly, patients should be instructed to restrict their salt intake to help achieve net fluid loss. Thirdly, the patient may require IV diuretic therapy to avoid the poor bioavailability frequently encountered due to reduced gastrointestinal blood flow, reduced intestinal peristalsis, and intestinal mucosal oedema. A Cochrane review [79] has confirmed that continuous IV furosemide infusion achieves a greater diuresis than bolus 
IV doses and this is associated with reduced mortality and shorter hospital stay. Other treatment options include adding in a thiazide diuretic to block distal sodium reabsorption, a potassium-sparing diuretic such as spironolactone, or adding salt-poor albumin. Salt-poor albumin is thought to enhance delivery of furosemide to the kidney, and one small study suggested adding salt-poor albumin to a furosemide infusion significantly increased sodium excretion [80].

5.2. Angiotensin-Converting Enzyme (ACE) Inhibitors. ACE inhibitors are known to reduce mortality in patients with heart failure [81], though the majority of these studies excluded patients with significant renal impairment. The Cooperative North Scandinavian Enalapril Survival (CONSENSUS) study revealed that patients with the most severe CCF had a substantial increase in creatinine on initiation of an ACE inhibitor irrespective of baseline creatinine [82]. However, it is comforting to note that in the CONSENSUS trial the outcomes were better in the treatment arm even though mean creatinine increased. Indeed, some have proposed that the rise in creatinine after initiation of an ACE inhibitor actually may identify the subgroup of patients who derive the most benefit [83].

ACE inhibitors should be used with caution in patients with CRS and renal functional monitored closely during initiation and uptitration. This caution should not, however, be used to avoid ACE inhibitor therapy. Studies have shown that patients with first presentation of pulmonary oedema are frequently discharged without initiation of ACE inhibitor therapy for fear of worsening renal function [84]. However, as mentioned above, patients who derive prognostic benefit over the longer term from these drugs may experience slight deterioration of renal function in the short term. A concomitant reduction in diuretic dosage may be required (especially once the patient is euvolemic) to facilitate safe uptitration of the ACE inhibitor. The chances of deterioration of renal function after starting ACE inhibitor therapy can also be minimised by avoiding simultaneous use of NSAIDs and ensuring the patient is not hypovolemic at onset of treatment.

5.3. Inotropic Support: The Controversy Continues. Patients with CRS are often hypotensive, and admissions due to ADHF frequently result in severe hypotensive episodes or frank cardiogenic shock. This may be accompanied by oligoanuria, and inotropes are frequently used in this setting with the aim of improving cardiac output and thus renal blood flow. "Renal" or low-dose dopamine is known to increase renal blood flow [85] though there is conflicting evidence regarding its effect upon GFR $[85,86]$. One study of 13 patients suggested that dopamine reduces renovascular resistance [87], though the baseline renal function of these patients is not stated. However, another larger study-in which $75 \%$ had acute renal failure-showed an increase in renovascular resistance in these patients with a fall in resistance in those with normal renal function [88]. Most importantly, no clinical trial to date has demonstrated a mortality benefit [89].

Trials of dobutamine and milrinone have shown improvement of cardiac index and, in proportion, renal blood flow-however, this has not translated into mortality benefit. The Outcomes of a Prospective Trial of Intravenous Milrinone for Exacerbations of a Chronic Heart Failure (OPTIME-HF) trial clearly rejected the hypothesis that milrinone would improve renal function and overall survival in ADHF patients [90].

The patient population who requires inotropic support for $\mathrm{ADHF}$ or cardiogenic shock is inherently complex, and thus designing adequately powered and well-conducted randomised trials poses clear challenges. However, it seems likely that short-term inotropic support for such patients in a low-output state is likely to continue. Current ESC heart failure guidelines state the evidence for using dobutamine as class IIa level B, dopamine class IIa level C, milrinone class IIb level B, and levosimendan class IIa level B (i.e., none has a class I or level of evidence A recommendation) [57].

5.4. Nesiritide: Hope Turns to Hype? Certain pharmacological agents-which held much promise during developmenthave failed to make the expected impact following results of phase III clinical trials. Nesiritide is an analogue of brain natriuretic peptide (BNP) and known to induce vasodilation and reduce filling pressures as well as augment cardiac output. The first large randomised trial of nesiritide in patients with CRS demonstrated no difference in GFR, renal plasma flow, urine output, sodium excretion, or mortality between treatment and placebo groups [91]. A meta-analysis of seven large randomised trials of nesiritide also showed a lack of mortality benefit at 30-day and 180-day followup [92]. A pooled analysis of three trials showed a strong trend ( $P$ value .057 ) towards increased early mortality with nesiritide [93]. The results of the Acute Study of Clinical Effectiveness of Nesiritide in Decompensated Heart Failure Trial (ASCEND) [94] are currently awaited and may help clarify if this agent has a future in the management of CRS (type 2) patients.

\section{Future Directions in CRS}

The ability to make a diagnosis of CRS early in a patient's assessment may allow early introduction of management strategies which would hopefully prevent further clinical and biochemical deterioration. Therefore, the development of novel biomarkers of acute kidney injury is a promising step. Neutrophil gelatinase-associated lipocalin [95], cystatin C [96], kidney injury molecule-1 [97], N-acetyl$\beta$-(D)glucosaminidase [98], and interleukin-18 [99] have all been shown to act as markers of renal injury in a variety of different clinical scenarios, and further work is ongoing to help define their role in diagnosis and management.

Patients resistant to diuretic therapy may benefit from ultrafiltration (UF) or aquapheresis. This extracorporeal treatment permits removal of large fluid volumes more 
speedily than diuretics and without inducing profound hypotension. The UNLOAD trial showed that, 48 hours after treatment, UF safely produced greater weight and net fluid loss than conventional IV diuretic therapy and at 90 days the UF group had fewer repeat admissions to hospital for fluid reaccumulation [100]. However, another trial demonstrated that UF did not improve renal haemodynamics (as judged by urine output, eGFR, and renal plasma flow) [101].

Arginine vasopressin (AVP) is released from the posterior pituitary gland and mediates water retention via the $\mathrm{V}_{2}$ receptor in the renal collecting ducts. AVP levels are elevated in heart failure patients and AVP antagonists (the "vaptans") have thus been developed. Tolvaptan was initially shown to reduce body weight and help normalize serum sodium in ADHF patients without adverse effect on blood pressure, heart rate, or renal function [102]. Later studies also demonstrated that tolvaptan, when compared to placebo, significantly reduced pulmonary arterial pressure, pulmonary capillary wedge pressure, and right atrial pressure as well as increasing urine output without adverse effect on renal function [103]. The multicentre international phase III Efficacy of Vasopressin Antagonism in Heart Failure Outcome Study with Tolvaptan (EVEREST) trial [104] randomised patients admitted with ADHF within 48 hours to receive either tolvaptan $30 \mathrm{mg}$ once daily or placebo for a minimum time duration of 60 days. Tolvaptan was associated with more weight loss and less dyspnoea on days 1 and 7 and without adverse effect on renal function. However, the key end points of all-cause mortality, cardiovascular mortality, cardiovascular death, or hospitalization, and worsening heart failure were not different between the two groups [104].

Adenosine-A1 receptors are found in the kidney and thought to mediate urine output. Adenosine levels are increased in heart failure [105] and thus adenosine-A1 receptor antagonists were conceived; unfortunately, again, the vital randomised trial failed to show any benefit in ADHF patients [106].

CCF patients characteristically have an expanded extracellular fluid volume and contracted arterial blood volume with resultant regional perfusion abnormalities. This results in a series of complex neurohormonal changes leading to peripheral and central congestion and reduced renal blood flow [107]. Hypertonic saline solution (HSS) has been proposed as a useful adjunct to IV furosemide in ADHF patients with CRS with several postulated mechanisms of action: mobilisation of fluid from the extravascular space to the intravascular compartment by the osmotic effects of HSS and an increase in renal blood flow which can thus help overcome diuretic resistance [108]. Small studies have demonstrated the ability of HSS to augment renal blood flow and a larger trial — which randomised NYHA class 4 patients to IV furosemide plus HSS or IV furosemide bolus alonerevealed a greater degree of diuresis and natriuresis, lower rehospitalisation rate, and lower mortality rate in the HSS group versus placebo group [109]. However, routine use of HSS in ADHF patients remains rare, and its role in this patient population is yet to be defined.

\section{Conclusion}

As our review has hopefully demonstrated, CRS is an ominent development in many patients. However, prognosis is not uniform across all five subtypes and highly dependent upon the nature of the underlying disease process(es). The worst prognoses are in those with chronic dysfunction of both organ systems. CRS has generally been used so far to describe patients with renal dysfunction secondary to chronic heart failure; this group of patients have a particularly high morbidity and mortality. Difficulties remain regarding diagnostic pathways and appropriate management strategies. Fortunately, however, cardiologists and nephrologists are now acutely aware of the scale of the problem posed by CRS, and this "awakening" will hopefully translate into greater research into this fascinating yet challenging clinical conundrum.

\section{Conflict of Interests}

The authors declare no conflict of interests.

\section{Abbreviations}

ACE: Angiotensin-converting enzyme

ADHF: Acute decompensated heart failure

AVP: Arginine vasopressin

BNP: Brain natriuretic peptide

CCF: Congestive cardiac failure

CKD: Chronic kidney disease

CRAS: Cardiorenal anaemia syndrome

CRS: Cardiorenal syndrome

ECFV: Extracellular fluid volume

ESC: European Society of Cardiology

ESRF: End-stage renal failure

GFR: Glomerular filtration rate

HSS: Hypertonic saline solution

IAP: Intrababdominal pressure

IV: Intravenous

LV: $\quad$ Left ventricle

NO: $\quad$ Nitric oxide

NPY: Neuropeptide Y

NSAID: Nonsteroidal anti-inflammatory drug

RAAS: Renin-angiotensin-aldosterone-system

ROS: Reactive oxygen species

SNS: $\quad$ Sympathetic nervous system

UF: Ultrafiltration.

\section{References}

[1] J. T. Heywood, "The cardiorenal syndrome: lessons from the ADHERE database and treatment options," Heart Failure Reviews, vol. 9, no. 3, pp. 195-201, 2005.

[2] NHLBI Working Group, "Cardiorenal connections in heart failure and cardiovascular disease," National Heart, Lung and Blood Institute Website, October 2009, http://www.nhlbi .nih.gov/meetings/workshops/cardiorenal-hf-hd.htm.

[3] C. Geisberg and J. Butler, "Addressing the challenges of cardiorenal syndrome," Cleveland Clinic Journal of Medicine, vol. 73, no. 5, pp. 485-491, 2006. 
[4] K. F. Adams Jr., G. C. Fonarow, C. L. Emerman et al., "Characteristics and outcomes of patients hospitalised for heart failure in the United States: rationale, design and preliminary observations from the first 100,000 cases in the Acute Decompensated Heart Failure National Registry (ADHERE)," American Heart Journal, vol. 149, pp. 209-216, 2005.

[5] F. A. McAlister, J. Ezekowitz, M. Tonelli, and P. W. Armstrong, "Renal insufficiency and heart failure: prognostic and therapeutic implications from a prospective cohort study," Circulation, vol. 109, no. 8, pp. 1004-1009, 2004.

[6] M. G. Shlipak and B. M. Massie, "The clinical challenge of cardiorenal syndrome," Circulation, vol. 110, no. 12, pp. 1514-1517, 2004.

[7] H. L. Hillege, A. R. J. Girbes, P. J. de Kam et al., "Renal function, neurohormonal activation, and survival in patients with chronic heart failure," Circulation, vol. 102, no. 2, pp. 203-210, 2000.

[8] D. E. Forman, J. Butler, Y. Wang et al., "Incidence, predictors at admission, and impact of worsening renal function among patients hospitalized with heart failure," Journal of the American College of Cardiology, vol. 43, no. 1, pp. 61-67, 2004.

[9] National Institutes of Health, "National Institute of Diabetes and Digestive and Kidney diseases," Annual Data Report, USRDS, Bethesda, Md, USA, 1997, http://www.usrds.org/.

[10] M. Tonelli, N. Wiebe, B. Culleton et al., "Chronic kidney disease and mortality risk: a systematic review," Journal of the American Society of Nephrology, vol. 17, no. 7, pp. 2034-2047, 2006.

[11] A. E. G. Raine, R. Margreiter, F. P. Brunner et al., "Report on management of renal failure in Europe, XXII, 1991," Nephrology Dialysis Transplantation, vol. 7, no. 2, pp. 7-35, 1992.

[12] C. A. Herzog, J. Z. Ma, and A. J. Collins, "Poor long-term survival after acute myocardial infarction among patients on long-term dialysis," New England Journal of Medicine, vol. 339, no. 12, pp. 799-805, 1998.

[13] K. Greaves, R. Chen, L. Ge et al., "Mild to moderate renal impairment is associated with increased left ventricular mass," International Journal of Cardiology, vol. 124, no. 3, pp. 384-386, 2008.

[14] R. K. Wali, G. S. Wang, S. S. Gottlieb et al., "Effect of kidney transplantation on left ventricular systolic dysfunction and congestive heart failure in patients with end-stage renal disease," Journal of the American College of Cardiology, vol. 45, no. 7, pp. 1051-1060, 2005.

[15] P. S. Parfrey, J. D. Harnett, R. N. Foley et al., "Impact of renal transplantation on uremic cardiomyopathy," Transplantation, vol. 60, no. 9, pp. 908-914, 1995.

[16] R. K. Burt, S. Gupta-Burt, W. N. Suki, C. G. Barcenas, J. J. Ferguson, and C. T. van Buren, "Reversal of left ventricular dysfunction after renal transplantation," Annals of Internal Medicine, vol. 111, no. 8, pp. 635-640, 1989.

[17] S. R. C. Ferreira, V. A. Moisés, A. Tavares, and A. PachecoSilva, "Cardiovascular effects of successful renal transplantation: a 1-year sequential study of left ventricular morphology and function, and 24-hour blood pressure profile," Transplantation, vol. 74, no. 11, pp. 1580-1587, 2002.

[18] C. Ronco, M. Haapio, A. A. House, N. Anavekar, and R. Bellomo, "Cardiorenal syndrome," Journal of the American College of Cardiology, vol. 52, no. 19, pp. 1527-1539, 2008.

[19] C. Ronco, P. McCullough, S. D. Anker et al., "Cardio-renal syndromes: report from the consensus conference of the acute dialysis quality initiative," European Heart Journal, vol. 31, no. 6, pp. 703-711, 2010.

[20] L. G. Bongartz, M. J. Cramer, P. A. Doevendans, J. A. Joles, and B. Braam, "The severe cardiorenal syndrome: 'Guyton revisited'” European Heart Journal, vol. 26, no. 1, pp. 11-17, 2005.

[21] P. J. Cannon, “The kidney in heart failure," New England Journal of Medicine, vol. 296, no. 1, pp. 26-32, 1977.

[22] A. Nohria, V. Hasselblad, A. Stebbins et al., "Cardiorenal interactions. Insights from the ESCAPE trial," Journal of the American College of Cardiology, vol. 51, no. 13, pp. 12681274, 2008.

[23] M. S. Weinfeld, G. M. Chertow, and L. W. Stevenson, "Aggravated renal dysfunction during intensive therapy for advanced chronic heart failure," American Heart Journal, vol. 138, no. 2, pp. 285-290, 1999.

[24] W. Mullens, Z. Abrahams, G. S. Francis et al., "Importance of venous congestion for worsening of renal function in advanced decompensated heart failure," Journal of the American College of Cardiology, vol. 53, no. 7, pp. 589-596, 2009.

[25] C. W. Yancy, M. Lopatin, L. W. Stevenson, T. de Marco, and G. C. Fonarow, "Clinical presentation, management, and in-hospital outcomes of patients admitted with acute decompensated heart failure with preserved systolic function: a report from the Acute Decompensated Heart Failure National Registry (ADHERE) database," Journal of the American College of Cardiology, vol. 47, no. 1, pp. 76-84, 2006.

[26] M. E. Pueyo, W. Gonzalez, A. Nicoletti, F. Savoie, J. F. Arnal, and J. B. Michel, "Angiotensin II stimulates endothelial vascular cell adhesion molecule-1 via nuclear factor- $\kappa \mathrm{B}$ activation induced by intracellular oxidative stress," Arteriosclerosis, Thrombosis, and Vascular Biology, vol. 20, no. 3, pp. 645-651, 2000.

[27] M. Ushio-Fukai, A. M. Zafari, T. Fukui, N. Ishizaka, and K. K. Griendling, "p22(phox) is a critical component of the superoxide-generating NADH/NADPH oxidase system and regulates angiotensin II-induced hypertrophy in vascular smooth muscle cells," Journal of Biological Chemistry, vol. 271, no. 38, pp. 23317-23321, 1996.

[28] T. Chabrashvili, C. Kitiyakara, J. Blau et al., "Effects of ANG II type 1 and 2 receptors on oxidative stress, renal NADPH oxidase, and SOD expression," American Journal of PhysiologyRegulatory Integrative and Comparative Physiology, vol. 285, no. 1, pp. R117-R124, 2003.

[29] H. Nakagami, M. Takemoto, and J. K. Liao, "NADPH oxidase-derived superoxide anion mediates angiotensin IIinduced cardiac hypertrophy," Journal of Molecular and Cellular Cardiology, vol. 35, no. 7, pp. 851-859, 2003.

[30] J. S. Bock and S. S. Gottlieb, "Cardiorenal syndrome: new perspectives," Circulation, vol. 121, no. 23, pp. 2592-2600, 2010.

[31] A. P. Zou, N. Li, and A. W. Cowley Jr., "Production and actions of superoxide in the renal medulla," Hypertension, vol. 37, no. 2, pp. 547-553, 2001.

[32] V. Witko-Sarsat, M. Friedlander, T. N. Khoa et al., "Advanced oxidation protein products as novel mediators of inflammation and monocyte activation in chronic renal failure," Journal of Immunology, vol. 161, no. 5, pp. 2524-2532, 1998.

[33] V. Witko-Sarsat, M. Friedlander, C. Capeillère-Blandin et al., "Advanced oxidation protein products as a novel marker of oxidative stress in uremia," Kidney International, vol. 49, no. 5, pp. 1304-1313, 1996.

[34] T. Miyata, K. Maeda, K. Kurokawa, and C. van Ypersele de Strihou, "Oxidation conspires with glycation to generate 
noxious advanced glycation end products in renal failure," Nephrology Dialysis Transplantation, vol. 12, no. 2, pp. 255258, 1997.

[35] E. Maggi, R. Bellazzi, A. Gazo, M. Seccia, and G. Bellomo, "Autoantibodies against oxidatively-modified LDL in uremic patients undergoing dialysis," Kidney International, vol. 46, no. 3, pp. 869-876, 1994.

[36] M. F. Hill and P. K. Singal, "Antioxidant and oxidative stress changes during heart failure subsequent to myocardial infarction in rats," American Journal of Pathology, vol. 148, no. 1, pp. 291-300, 1996.

[37] K. Leineweber, I. Heinroth-Hoffmann, K. Pönicke, G. Abraham, B. Osten, and O. E. Brodde, "Cardiac $\beta$-adrenoceptor desensitization due to increased $\beta$-adrenoceptor kinase activity in chronic uremia," Journal of the American Society of Nephrology, vol. 13, no. 1, pp. 117-124, 2002.

[38] M. R. Bristow, R. Ginsburg, W. Minobe et al., "Decreased catecholamine sensitivity and $\beta$-adrenergic-receptor density in failing human hearts," New England Journal of Medicine, vol. 307, no. 4, pp. 205-211, 1982.

[39] J. K. Amin, L. Xiao, D. R. Pimental et al., "Reactive oxygen species mediate alpha-adrenergic receptor-stimulated hypertrophy in adult rat ventricular myocytes," Journal of Molecular and Cellular Cardiology, vol. 33, no. 1, pp. 131-139, 2001.

[40] G. Jackson, C. R. Gibbs, M. K. Davies, and G. Y. Lip, "ABC of heart failure. Pathophysiology," British Medical Journal, vol. 320, no. 7228, pp. 167-170, 2000.

[41] L. Li, E. W. Lee, H. Ji, and Z. Zukowska, "Neuropeptide Y-induced acceleration of postangioplasty occlusion of rat carotid artery," Arteriosclerosis, Thrombosis, and Vascular Biology, vol. 23, no. 7, pp. 1204-1210, 2003.

[42] Z. Zukowska-Grojec, "Neuropeptide Y-A novel sympathetic stress hormone and more," Annals of the New York Academy of Sciences, vol. 771, pp. 219-233, 1995.

[43] H. Krum, M. Schlaich, R. Whitbourn et al., "Catheter-based renal sympathetic denervation for resistant hypertension: a multicentre safety and proof-of-principle cohort study," The Lancet, vol. 373, no. 9671, pp. 1275-1281, 2009.

[44] M. P. Schlaich, P. A. Sobotka, H. Krum, E. Lambert, and M. D. Esler, "Renal sympathetic-nerve ablation for uncontrolled hypertension," New England Journal of Medicine, vol. 361, no. 9, pp. 932-934, 2009.

[45] F. R. Winton, "The influence of venous pressure on the isolated mammalian kidney," Journal of Physiology, vol. 72, pp. 49-61, 1931.

[46] S. E. Bradley and G. P. Bradley, "The effect of increased intraabdominal pressure on renal function in man," Journal of Clinical Investigation, vol. 26, pp. 1010-1015, 1947.

[47] M. L. N. G. Malbrain, M. L. Cheatham, A. Kirkpatrick et al., "Results from the international conference of experts on intra-abdominal hypertension and abdominal compartment syndrome. I. Definitions," Intensive Care Medicine, vol. 32, no. 11, pp. 1722-1732, 2006.

[48] W. Mullens, Z. Abrahams, H. N. Skouri et al., "Elevated intraabdominal pressure in acute decompensated heart failure. A potential contributor to worsening renal function?" Journal of the American College of Cardiology, vol. 51, no. 3, pp. 300306, 2008.

[49] K. Damman, V. M. van Deursen, G. Navis, A. A. Voors, D. J. van Veldhuisen, and H. L. Hillege, "Increased central venous pressure is associated with impaired renal function and mortality in a broad spectrum of patients with cardiovascular disease," Journal of the American College of Cardiology, vol. 53, no. 7, pp. 582-588, 2009.

[50] M. H. Drazner, J. E. Rame, L. W. Stevenson, and D. L. Dries, "Prognostic importance of elevated jugular venous pressure and a third heart sound in patients with heart failure," New England Journal of Medicine, vol. 345, no. 8, pp. 574-581, 2001.

[51] D. S. Silverberg, D. Wexler, M. Blum et al., "The correction of anemia in severe resistant heart failure with erythropoietin and intravenous iron prevents the progression of both the heart and the renal failure and markedly reduces hospitalization," Clinical Nephrology, vol. 58, pp. S37-S45, 2002.

[52] R. P. Silva, P. H. U. Barbosa, O. S. Kimura et al., "Prevalance of anemia and its association with cardio-renal syndrome," International Journal of Cardiology, vol. 120, no. 2, pp. 232236, 2007.

[53] E. O’Meara, T. Clayton, M. B. McEntegart et al., "Clinical correlates and consequences of anemia in a broad spectrum of patients with heart failure-results of the candesartan in heart failure: assessment of reduction in mortality and morbidity (CHARM) program," Circulation, vol. 113, no. 7, pp. 986-994, 2006.

[54] L. Gotloib, D. Silverberg, R. Fudin, and A. Shostak, "Iron deficiency is a common cause of anemia in chronic kidney disease and can often be corrected with intravenous iron," Journal of Nephrology, vol. 19, no. 2, pp. 161-167, 2006.

[55] J. N. Nanas, C. Matsouka, D. Karageorgopoulos et al., "Etiology of anemia in patients with advanced heart failure," Journal of the American College of Cardiology, vol. 48, no. 12, pp. 2485-2489, 2006.

[56] S. D. Anker, J. C. Colet, G. Filippatos et al., "Ferric carboxymaltose in patients with heart failure and iron deficiency," New England Journal of Medicine, vol. 361, no. 25, pp. 24362448, 2009.

[57] K. Dickstein, A. Cohen-Solal, G. Filippatos et al., "ESC Guidelines for the diagnosis and treatment of acute and chronic heart failure 2008," European Heart Journal, vol. 29, no. 19, pp. 2388-2442, 2008.

[58] L. Calvillo, R. Latini, J. Kajstura et al., "Recombinant human erythropoietin protects the myocardium from ischemiareperfusion injury and promotes beneficial remodeling," Proceedings of the National Academy of Sciences of the United States of America, vol. 100, no. 8, pp. 4802-4806, 2003.

[59] C. J. Parsa, A. Matsumoto, J. Kim et al., "A novel protective effect of erythropoietin in the infarcted heart," Journal of Clinical Investigation, vol. 112, no. 7, pp. 999-1007, 2003.

[60] D. Burger, M. Lei, N. Geoghegan-Morphet, X. Lu, A. Xenocostas, and Q. Feng, "Erythropoietin protects cardiomyocytes from apoptosis via up-regulation of endothelial nitric oxide synthase," Cardiovascular Research, vol. 72, no. 1, pp. 51-59, 2006.

[61] D. M. Mancini, S. D. Katz, C. C. Lang, J. LaManca, A. Hudaihed, and A. S. Androne, "Effect of erythropoietin on exercise capacity in patients with moderate to severe chronic heart failure," Circulation, vol. 107, no. 2, pp. 294-299, 2003.

[62] P. van der Meer, A. A. Voors, E. Lipsic, T. D. J. Smilde, W. H. van Gilst, and D. J. van Veldhuisen, "Prognostic value of plasma erythropoietin on mortality in patients with chronic heart failure," Journal of the American College of Cardiology, vol. 44, no. 1, pp. 63-67, 2004.

[63] J. George, S. Patal, D. Wexler et al., "Circulating erythropoietin levels and prognosis in patients with congestive heart failure comparison with neurohormonal and inflammatory 
markers," Archives of Internal Medicine, vol. 165, no. 11, pp. 1304-1309, 2005.

[64] P. van der Meer, D. J. Lok, J. L. Januzzi et al., "Adequacy of endogenous erythropoietin levels and mortality in anaemic heart failure patients," European Heart Journal, vol. 29, no. 12 , pp. 1510-1515, 2008

[65] T. B. Drueke, F. Locatelli, N. Clyne et al., "Normalization of haemoglobin level in patients with chronic kidney disease and anaemia," New England Journal of Medicine, vol. 355, pp. 2071-2084, 2006.

[66] M. A. Pfeffer, E. A. Burdmann, C. Y. Chen et al., "A trial of darbepoetin alfa in type 2 diabetes and chronic kidney disease," New England Journal of Medicine, vol. 361, no. 21, pp. 2019-2032, 2009.

[67] A. K. Singh, L. Szczech, K. L. Tang et al., "Correction of anemia with epoetin alfa in chronic kidney disease," New England Journal of Medicine, vol. 355, no. 20, pp. 2085-2098, 2006.

[68] D. J. van Veldhuisen, K. Dickstein, A. Cohen-Solal et al., "Randomized, double-blind, placebo-controlled study to evaluate the effect of two dosing regimens of darbepoetin alfa in patients with heart failure and anaemia," European Heart Journal, vol. 28, no. 18, pp. 2208-2216, 2007.

[69] M. G. Shlipak, "Pharmacotherapy for heart failure in patients with renal insufficiency," Annals of Internal Medicine, vol. 138, no. 11, pp. 917-924, 2003.

[70] S. S. Gottlieb, D. C. Brater, I. Thomas et al., "BG9719 (CVT124), an A1 adenosine receptor antagonist, protects against the decline in renal function observed with diuretic therapy," Circulation, vol. 105, no. 11, pp. 1348-1353, 2002.

[71] J. Butler, D. E. Forman, W. T. Abraham et al., "Relationship between heart failure treatment and development of worsening renal function among hospitalized patients," American Heart Journal, vol. 147, no. 2, pp. 331-338, 2004.

[72] G. W. Neuberg, A. B. Miller, C. M. O'Connor et al., "Diuretic resistance predicts mortality in patients with advanced heart failure," American Heart Journal, vol. 144, no. 1, pp. 31-38, 2002.

[73] S. M. Bagshaw, A. Delaney, M. Haase, W. A. Ghali, and R. Bellomo, "Loop diuretics in the management of acute renal failure: a systematic review and meta-analysis," Critical Care and Resuscitation, vol. 9, no. 1, pp. 60-68, 2007.

[74] R. L. Mehta, M. T. Pascual, S. Soroko, and G. M. Chertow, "Diuretics, mortality, and nonrecovery of renal function in acute renal failure," Journal of the American Medical Association, vol. 288, no. 20, pp. 2547-2553, 2002.

[75] D. H. Ellison, "Diuretic drugs and the treatment of edema: from clinic to bench and back again," American Journal of Kidney Diseases, vol. 23, no. 5, pp. 623-643, 1994.

[76] D. C. Brater, B. Day, A. Burdette, and S. Anderson, "Bumetanide and furosemide in heart failure," Kidney International, vol. 26, no. 2, pp. 183-189, 1984.

[77] D. C. Brater, "Analysis of the effect of indomethacin on the response to furosemide in man: effect of dose of furosemide," Journal of Pharmacology and Experimental Therapeutics, vol. 210, no. 3, pp. 386-390, 1979.

[78] N. Pokhrel, N. Maharjan, B. Dhakal, and R. R. Arora, "Cardiorenal syndrome: a literature review," Experimental and Clinical Cardiology, vol. 13, no. 4, pp. 165-170, 2008.

[79] D. R. Salvador, N. R. Rey, G. C. Ramos, and F. E. Punzalan, "Continuous infusion versus bolus injection of loop diuretics in congestive heart failure," Cochrane Database of Systematic Reviews, no. 1, Article ID CD003178, 2004.
[80] M. Inoue, K. Okajima, K. Itoh et al., "Mechanism of furosemide resistance in analbuminemic rats and hypoalbuminemic patients," Kidney International, vol. 32, no. 2, pp. 198-203, 1987.

[81] The SOLVD investigators, "Effect of enalapril on survival in patients with reduced left ventricular ejection fractions and congestive heart failure," New England Journal of Medicine, vol. 325, pp. 293-302, 1992.

[82] S. Ljungman, J. Kjekshus, and K. Swedberg, "Renal function in severe congestive heart failure during treatment with Enalapril (the Cooperative North Scandinavian Enalapril Survival Study [CONSENSUS] trial)," American Journal of Cardiology, vol. 70, no. 4, pp. 479-487, 1992.

[83] G. L. Bakris and M. R. Weir, "Angiotensin-converting enzyme inhibitor-associated elevations in serum creatinine: is this a cause for concern?" Archives of Internal Medicine, vol. 160, no. 5, pp. 685-693, 2000.

[84] M. Echemann, F. Zannad, S. Briançon et al., "Determinants of angiotensin-converting enzyme inhibitor prescription in severe heart failure with left ventricular systolic dysfunction: the EPICAL study," American Heart Journal, vol. 139, no. 4, pp. 624-631, 2000.

[85] R. H. McDonald, L. I. Goldberg, J. L. McNay, and E. P. Tuttle, "Effects of dopamine in man: augmentation of sodium excretion, glomerular filtration rate and renal plasma flow," Journal of Clinical Investigation, vol. 43, pp. 1116-1124, 1964.

[86] B. Ramdohr, G. Biamino, and R. Schröder, "Vergleichende Untersuchungen über die Wirkung von Dopamin und Orciprenalin am gesunden Menschen: Muskeldurchblutung, Nierendurchblutung, Nierenfunktion," Klinische Wochenschrift, vol. 50, no. 3, pp. 149-157, 1972.

[87] U. Elkayam, T. M. H. Ng, P. Hatamizadeh, M. Janmohamed, and A. Mehra, "Renal vasodilatory action of dopamine in patients with heart failure: magnitude of effect and site of action," Circulation, vol. 117, no. 2, pp. 200-205, 2008.

[88] A. Lauschke, U. Teichgräber, U. Frei, and K. U. Eckardt, "Low-dose' dopamine worsens renal perfusion in patients with acute renal failure," Kidney International, vol. 69, no. 9, pp. 1669-1674, 2006.

[89] P. Marik, "Low-dose dopamine: a systematic review," Intensive Care Medicine, vol. 28, no. 7, pp. 877-883, 2002.

[90] L. Klein, B. M. Massie, J. D. Leimberger et al., "Admission or changes in renal function during hospitalization for worsening heart failure predict post discharge survival: results from the Outcomes of a Prospective Trial of Intravenous Milrinone for Exacerbations of Chronic Heart Failure (OPTIMECHF)," Circulation: Heart Failure, vol. 1, pp. 25-33, 2008.

[91] D. J. Wang, T. C. Dowling, D. Meadows et al., "Nesiritide does not improve renal function in patients with chronic heart failure and worsening serum creatinine," Circulation, vol. 110, no. 12, pp. 1620-1625, 2004.

[92] R. R. Arora, P. K. Venkatesh, and J. Molnar, "Short and longterm mortality with nesiritide," American Heart Journal, vol. 152, no. 6, pp. 1084-1090, 2006.

[93] J. D. Sackner-Bernstein, M. Kowalski, M. Fox, and K. Aaronson, "Short-term risk of death after treatment with nesiritide for decompensated heart failure: a pooled analysis of randomized controlled trials," Journal of the American Medical Association, vol. 293, no. 15, pp. 1900-1905, 2005.

[94] A. F. Hernandez, C. M. O'Connor, R. C. Starling et al., "Rationale and design of the Acute Study of Clinical Effectiveness of Nesiritide in Decompensated Heart Failure Trial (ASCEND-HF)," American Heart Journal, vol. 157, no. 2, pp. 271-277, 2009. 
[95] K. Mori and K. Nakao, "Neutrophil gelatinase-associated lipocalin as the real-time indicator of active kidney damage," Kidney International, vol. 71, no. 10, pp. 967-970, 2007.

[96] S. Herget-Rosenthal, G. Marggraf, J. Hüsing et al., "Early detection of acute renal failure by serum cystatin C," Kidney International, vol. 66, no. 3, pp. 1115-1122, 2004.

[97] V. S. Vaidya, V. Ramirez, T. Ichimura, N. A. Bobadilla, and J. V. Bonventre, "Urinary kidney injury molecule-1: a sensitive quantitative biomarker for early detection of kidney tubular injury," American Journal of Physiology-Renal Physiology, vol. 290, no. 2, pp. F517-F529, 2006.

[98] O. Liangos, M. C. Perianayagam, V. S. Vaidya et al., "Urinary $\mathrm{N}$-acetyl- $\beta$-(D)-glucosaminidase activity and kidney injury molecule-1 level are associated with adverse outcomes in acute renal failure," Journal of the American Society of Nephrology, vol. 18, no. 3, pp. 904-912, 2007.

[99] C. R. Parikh, A. Jani, V. Y. Melnikov, S. Faubel, and C. L. Edelstein, "Urinary interleukin-18 is a marker of human acute tubular necrosis," American Journal of Kidney Diseases, vol. 43, no. 3, pp. 405-414, 2004.

[100] M. R. Costanzo, M. E. Guglin, M. T. Saltzberg et al., "Ultrafiltration versus intravenous diuretics for patients hospitalized for acute decompensated heart failure," Journal of the American College of Cardiology, vol. 49, no. 6, pp. 675683, 2007.

[101] H. L. Rogers, J. Marshall, J. Bock et al., "A randomized, controlled trial of the renal effects of ultrafiltration as compared to furosemide in patients with acute decompensated heart failure," Journal of Cardiac Failure, vol. 14, no. 1, pp. 1-5, 2008.

[102] M. Gheorghiade, I. Niazi, J. Ouyang et al., "Vasopressin V2receptor blockade with tolvaptan in patients with chronic heart failure: results from a double-blind, randomized trial," Circulation, vol. 107, no. 21, pp. 2690-2696, 2003.

[103] J. E. Udelson, C. Orlandi, J. Ouyang et al., "Acute hemodynamic effects of tolvaptan, a vasopressin $V_{2}$ receptor blocker, in patients with symptomatic heart failure and systolic dysfunction: an international, multicenter, randomized, placebo-controlled trial," Journal of the American College of Cardiology, vol. 52, no. 19, pp. 1540-1545, 2008.

[104] M. A. Konstam, M. Gheorghiade, J. C. Burnett Jr. et al., "Effects of oral tolvaptan in patients hospitalized for worsening heart failure: the EVEREST outcome trial," Journal of the American Medical Association, vol. 297, no. 12, pp. 1319-1331, 2007.

[105] H. Funaya, M. Kitakaze, K. Node, T. Minamino, K. Komamura, and M. Hori, "Plasma adenosine levels increase in patients with chronic heart failure," Circulation, vol. 95, no. 6, pp. 1363-1365, 1997.

[106] G. Cotter, H. C. Dittrich, B. Davison Weatherley et al., "The PROTECT pilot study: a randomized, placebo-controlled, dose-finding study of the adenosine A1 receptor antagonist rolofylline in patients with acute heart failure and renal impairment," Journal of Cardiac Failure, vol. 14, no. 8, pp. 631-640, 2008.

[107] M. Packer, "Neurohormonal interactions and adaptations in congestive heart failure," Circulation, vol. 77, no. 4, pp. 721730, 1988.

[108] S. Paterna, P. Di Pasquale, G. Parrinello et al., "Effects of highdose furosemide and small-volume hypertonic saline solution infusion in comparison with a high dose of furosemide as a bolus, in refractory congestive heart failure," European Journal of Heart Failure, vol. 2, no. 3, pp. 305-313, 2000.
[109] G. Licata, P. Di Pasquale, G. Parrinello et al., "Effects of highdose furosemide and small-volume hypertonic saline solution infusion in comparison with a high dose of furosemide as bolus in refractory congestive heart failure: long-term effects," American Heart Journal, vol. 145, no. 3, pp. 459-466, 2003. 


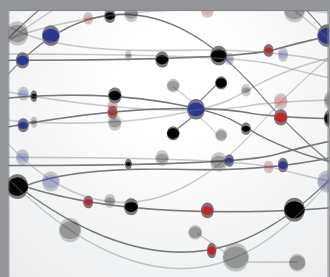

The Scientific World Journal
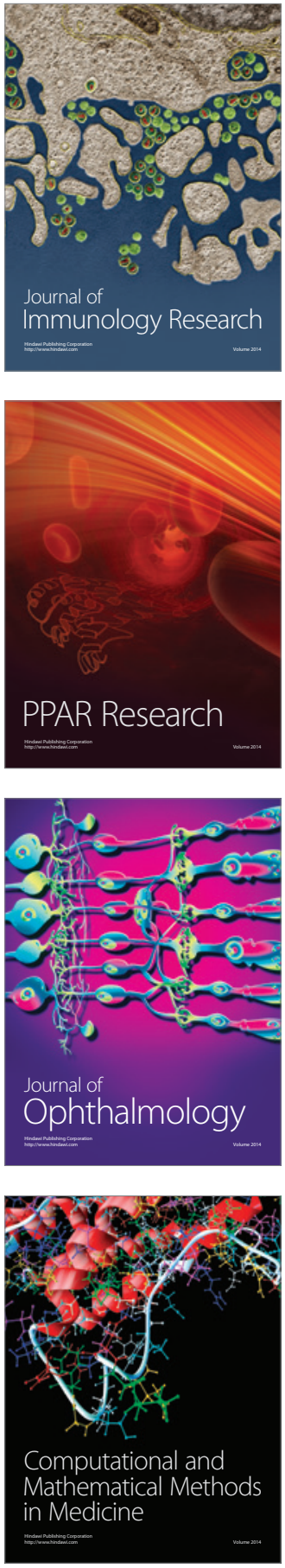

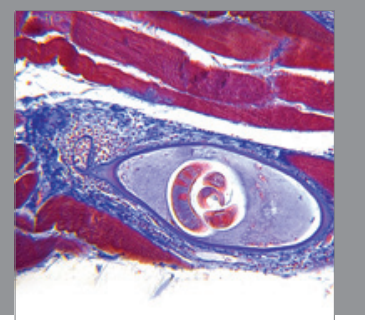

Gastroenterology

Research and Practice
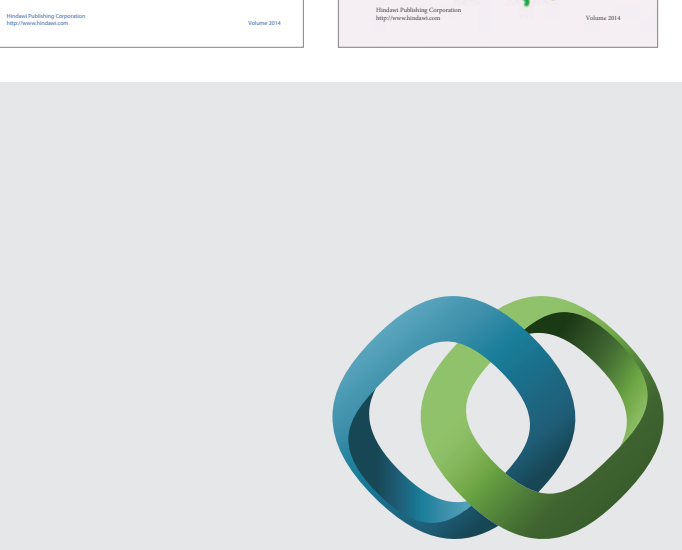

\section{Hindawi}

Submit your manuscripts at

http://www.hindawi.com
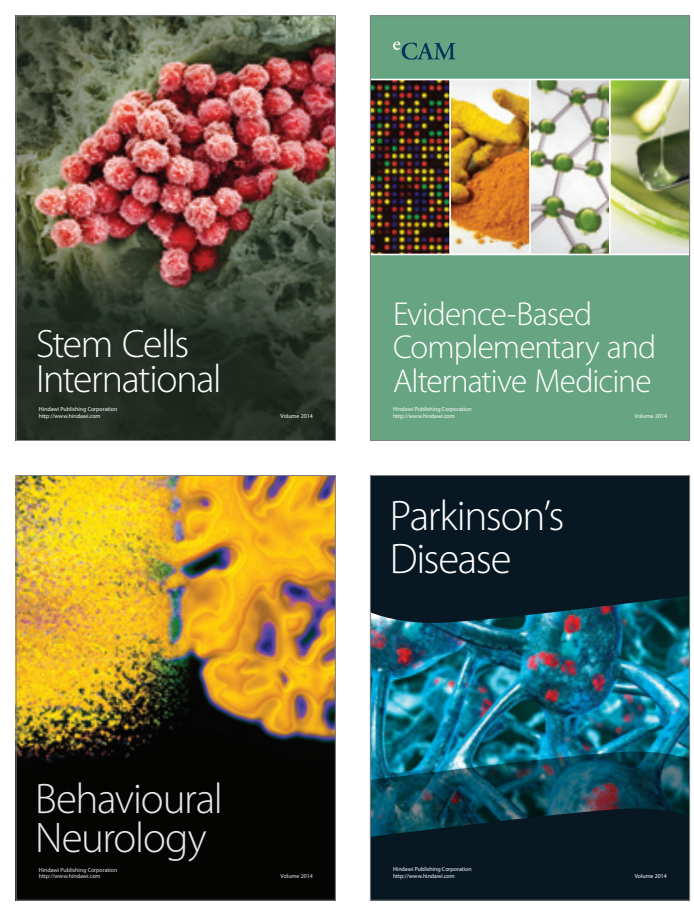

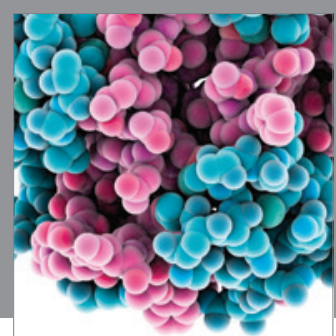

Journal of
Diabetes Research

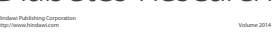

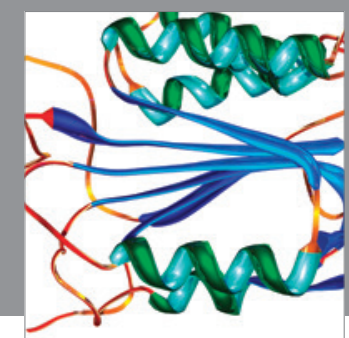

Disease Markers
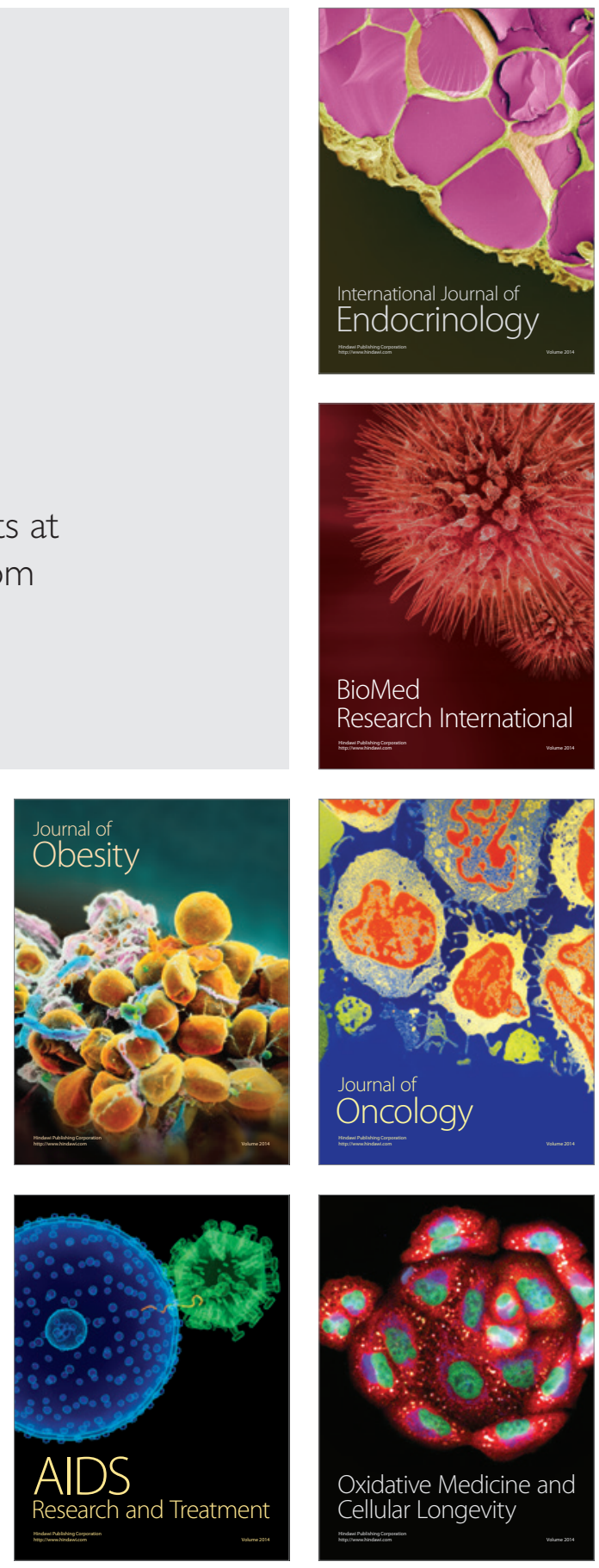